Original Research Paper

\title{
Adapatasi Rumah Joglo Akibat Alih Fungsi Bangunan Sebagai Pendukung Desa Wisata
}

\author{
Intan Kusumaningayu', Hanie Teki Tjendani2 ${ }^{*}$, Siti Muzaiyana ${ }^{1}$, Muhammad Rijal Amin ${ }^{1}$, Hilmi \\ Fauzaan Fajar ${ }^{1}$, Roihan Ikmaludin ${ }^{1}$, Sasa Aprilina ${ }^{1}$, Adi Prayogo ${ }^{1}$, Tiara Retnali Putri \\ Angguningtyas $^{2}$, Clarissa Rahma Anisadila ${ }^{2}$, Aviska Triayaska ${ }^{2}$, Trisna Alivto Danova ${ }^{2}$, Musthofa \\ Saifa Ardana ${ }^{2}$
}

${ }^{1}$ Prodi Arsitektur, Fakultas Teknik, Universitas 17 Agustus 1945 Surabaya, Indonesia.

${ }^{2}$ Prodi Teknik Sipil, Fakultas Teknik, Universitas 17 Agustus 1945 Surabaya, Indonesia.

https://doi.org/10.29303/jpmpi.v3i2.1345

Sitasi: Kusumaningayu, I., Tjendani, H. K., Muzaiyana, S., Amin, M. R., Fajar, M \& Muslim. B. (2022). Penguatan Ekonomi Masyarakat Melalui Pemanfaatan Lahan Pekarangan di Desa Merembu, Lombok Barat. Jurnal Pengabdian Magister Pendidikan IPA, 5(1)

\author{
Article history \\ Received: 11 Januari 2022 \\ Revised: 01 Februari 2022 \\ Accepted: 07 Februari 2022 \\ *Corresponding Author: Hanie \\ Teki Tjendani, Universitas 17 \\ Agustus 1945 Surabaya, \\ Surabaya, Indonesia; \\ Email: hanie@untag-sby.ac.id
}

\begin{abstract}
Rumah joglo merupakan rumah tradisional Jawa dengan nilai filosofi dan budaya yang sangat tinggi karena telah mampu mengintegrasikan beberapa aspek dalam kehidupan termasuk teknologi yang diterapkan dalam pembangunan rumah joglo tersebut. Di Desa Minggirsari Kecamatan Kanigoro Kabupaten Blitar terdapat sekitar 10 rumah joglo dengan berbagai kondisi baik yang masih terawat atau sebaliknya. Didukung dengan lokasi terletak di daerah aliran Sungai Brantas dengan peninggalan situs Patung Dwarapala, Desa Minggirsari telah ditetapkan sebagai Desa Wisata. Keberadaan rumah joglo sangat berpotensi meningkatkan nilai dari Desa Wisata karena fleksibilatas penggunaannya tanpa harus mengubah bentuk asli sehingga tidak menghilangkan nilai luhur dari rumah tradisional ini. Setelah terpilih 3 fungsi yang akan di adaptasi pada rumah joglo yaitu sebagai penginapan, rumah makan dan ruang pamer/ ruang belajar/ ruang diskusi maka dihasilkan gambar rencana berupa denah serta interior yang akan di aplikasikan pada rumah-rumah joglo yang sudah terpilih.
\end{abstract}

Keywords: Adaptasi Rumah Joglo; Desa Minggirsari; Desa Wisata;

\section{Pendahuluan}

$\mathrm{D}_{\mathrm{t}}$ aya tarik suatu kawasan desa wisata tidak terlepas dari latar belakang budaya dan kearifan lokal daerah tersebut. Rumah Joglo merupakan salah satu warisan budaya yang penyebarannya meliputi beberapa wilayah di Pulau Jawa.

Rancangan rumah joglo mempunyai filosofi yang begitu mendalam yang dianut secara turun temurun oleh masyarakat di Jawa. Rumah Joglo ini mempunyai arti pada bagianbagian bangunannya merupakan simbul dari doa dan harapan pemiliknya serta cara menjalani hidup yang baik (Brambel, 2020).

Tak hanya dalam kehidupan sehari-harinya saja, rumah adat dari Jawa Timur juga memiliki arti masing-masing yang melambangkan doa, harapan dan cara menjalani hidup yang baik. Memahami konsep rumah Jawa berarti memahami bagaimana rumah diartikan oleh masyarakat Jawa, serta nilai-nilai apa saja yang diterapkan dalam wujud fisik yang ada. Seiring dengan perkembangan zaman Rumah Joglo banyak mengalami perubahan baik dari segi bentuk 
maupun fungsinya. dapat diketahui bahwa terdapat makna yang mendalam pada rumah Jawa khususnya Joglo. Rumah joglo dibuat dan direncanakan berdasarkan filosofi yang dianut oleh masyarakatnya serta dituangkan secara menyeluruh dalam perancangan hunian Jawa berdasar kaidah yang diyakini.

Pada rumah Joglo terdiri dari 4 pilar yang menjadi simbol dari keberlanjutan kehidupan karena adanya keseimbangan antara aspekaspek sosial, ekonomi dan lingkungan. Selanjutnya budaya masyarakat setempat menjadi aspek penentu berhasil-tidaknya pelestarian falsafah yang telah ditanamkan oleh pendahulunya. Bila masyarakat setempat memiliki pemahaman positif akan peninggalan pendahulunya maka akan tercermin dalam pilihan bentuk bangunan yang digunakan walaupun perkembangan disain rumah tinggal terus berjalan. Kearifan lokal tercermin pada Rumah Joglo dengan empat tiang penyangga (4 soko guru) merupakan struktur utama yang kokoh sebagai penyangga tumpang sari berupa tumpukan balok yang akan membentuk kerangka atap agar mampu melindungi bangunan dibawahnya. Hal ini menunjukkan betapa pentingnya pendidikan karakter yang kuat agar mampu menjunjung tinggi nilai leluhur serta melindungi generasi yang akan datang(Wibawa dkk., 2019)

Seiring perjalanan waktu, pada beberapa tahun terakhir ini, fungsi rumah joglo banyak mengalami perubahan dan adaptasi dengan kebutuhan publik. Nilai estetis yang dimiliki bangunan-bangunan masa lalu memiliki daya tarik luar biasa dan banyak disukai kawula muda sehingga menjadi referensi dalam pengembangan bisnis. Hal ini sesuai dengan kondisi rumah joglo sebagai salah satu warisan budaya dengan berbagai filosofi yaitu memiliki ruang publik yang terintegrasi dalam upaya untuk mencari keselamatan hidup, menciptakan relasi dan menjaga keserasian dengan masyarakat sekitar; memiliki struktur yang dapat membangkitkan alam bawah sadar akan kemampuan mengenal karya arsitektural dimana pada umumnya mempunyai keterkaitan satu dengan lainnya; makna ruang publik pada rumah joglo dapat memberikan pemahaman pada para stakeholder terkait perencanaan ruang publik dengan memperhatikan kearifan lokal (Sumardiyanto dkk., 2016).

Pergantian fungsi serta kegiatan ini sangat dipengaruhi oleh perubahan mata pencaharian. Pada awalnya rumah joglo dipengaruhi oleh kegiatan pemiliknya dengan budaya agraris yaitu bertani dan bercocok tanam sedangkan pada saat ini terjadi perubahan fungsi ruangan akibat beralihnya kegiatan perekonomian dari ekonomi agraris ke ekonomi industri. Hal ini menyebabkan pemanfaatan ruang menjadi berubah mengikuti kegiatan dari pemilik rumah sehingga terdapat pengaruh antara kegiatan di suatu rumah dengan keberadaan ruang-ruang yang terdapat dalam rumah joglo. Perubahan ini tidak dapat dihindari namun dalam melestarikan arsitektur tradisional rumah joglo selain mempertahankan bentuk bangunan, pelestarian tata ruang adalah hal yang sangat penting untuk melestarikan nilai-nilai luhur dari susuna ruangan-ruangan tersebut (Maria Damiana Nestri Kiswari, 2019).

Dengan berbagai fleksibilas yang dimiliki rumah joglo maka sangat memungkinkan beberapa adaptasi fungsi dari bangunan tersebut. Demikian juga rumah-rumah joglo yang ada di Kecamatan Kanigoro Kabupaten Blitar. Pada umumnya rumah joglo yang ada di lokasi tersebut memiliki area yang sangat luas sedangkan pada beberapa rumah, para ahli waris dari pemilik rumah joglo tersebut memilih untuk bekerja dan tinggal di lokasi yang jauh dari rumah asal sehingga banyak bagian rumah yang dapat dimanfaatkan sebagai fasilitas umum yang di komersialkan.

Desa Minggirsari salah satu yang terletak di Kecamatan Kanigoro Kabupaten Blitar adalah sebuah desa dengan potensi sumber daya alam dan sumber daya manusia yang sangat besar. Lokasinya terletak di tepi Sungai Brantas dengan situs-situs peninggalan kerajaan di waktu lampau serta kemampuan penduduk dalam bertani, bercocok tanam, beternak sapi laktasi dan berbagai usaha industri rumah 
tangga. Berdasarkan data dari Dinas Peternakan Kabupeten Blitar pada tahun 2011, populasi sapi perah di Kecamatan Kanigoro sebanyak 1.244 ekor. Populasi sapi perah di Kecamatan Kanigoro menempati urutan keempat terbanyak diantara 22 kecamatan di Kabupaten Blitar (Ernawan dkk., 2016). Kondisi ini menjadikan Desa Minggirsari menjadi salah satu desa yang dikembangkan menjadi desa wisata.

Sebagai pendukungnya desa wisata perlu peran dari badan usaha milik desa (BUMDES) untuk menampung seluruh aktivitas perekonomian dan pelayanan umum yaitu kegiatan di bidang ekonomi serta pelayanan umum yang dilaksanakan oleh desa. BUMDES juga berperan penting dalam pengelolaan desa wisata misalnya dalam pengelolaan dan penjualan paket wisata hingga pengelolaan keuangannya sehingga dapat digunakan untuk biaya operasional dan pemeliharaan obyekobyek wisata yang ada di desa sehingga kegiatan perekonomian dan UMKM dapat berjalan selaras dan dapat meningkatkan taraf hidup masyarakat desa. BUMDES juga berperan dalam menggiatkan kelompok sadar wisata (pokdarwis) selaku pelaksana aktifitas pariwisata desa (Gautama dkk., 2020). Obyek wisata yang sedang dikembangkan di Desa Minggirsari antara lain situs Arca Dwarapala dan wisata arung sungai sebagi pendukungnya akan dilakukan alih fungsi rumah penduduk menjadi homestay, griya dedaharan dan ruang diskusi dan sinau bareng serta pamer produkproduk yang dihasilkan Desa Minggrisari. Rumah joglo yang terdapat di desa ini ada 10 lokasi namun dari semua itu untuk tahap pertama hanya 3 rumah joglo yang akan di alih fungsikan.

\section{Metode}

Pelaksanaan pengabdian masyarakat ini berdasarkan penelitian yang telah dilakukan sebelumnya oleh tim dan penulis yang sama. Telah terpilih 3 fungsi adaptasi dari 5 fungsi yang ditawarkan kepada para responden yang terdiri dari perangkat desa, karang taruna beserta kelompok sadar wisata (Pokdarwis) yaitu fungsi sebagai homestay/ penginapan, griya dedaharan/ rumah makan dan ruang belajar, diskusi serta ruang pameran hasil UKM Desa Minggirsari. Untuk Pemilihan lokasi disesuaikan dengan fungsi-fungsi yang diinginkan. Langkah-langkah yang dilakukan untuk keberhasilan dalam proses adaptasi Rumah Joglo akibat alih fungsi bangunan sebagai pendukung desa wisata yaitu :

1. Dilakukannya survei lokasi Rumah Joglo yang berada di Desa Minggirsari, Kecamatan Kanigoro, Kabupaten Blitar. Dengan mempertimbangkan aspek-aspek termasuk diantaranya: kemudahan akses menuju lokasi Rumah Joglo, dan jarak dengan lokasi situs Arca Dwarapala yang akan menjadi objek wisata. Kemudahan berkomunikasi dengan pemilih rumah atau ahli waris.

2. Melakukan pemetaan Rumah Joglo yang memungkinkan untuk dijadikan rumah singgah atau homestay, ruang sinau bareng, dan griya dedaharan. Dengan mempertimbangkan kelebihan dan kekurangan Rumah Joglo satu dengan yang lainnya.

3. Perencanaan fasilitas yang belum tersedia sebagai bentuk adaptasi Rumah Joglo sebagai pendukung desa wisata di Desa Minggirsari, Kecamatan Kanigoro, Kabupaten Blitar.

\section{Hasil dan Pembahasan}

Rumah Joglo 1 : dijadikan sebagai Homestay / Guest House / Griya Penginapan. Dibangun pada tahun 1930 oleh Bapak Sukono, Desa Minggrisari, Kecamatan Kanigoro, Kabupaten Blitar. Rumah Joglo ini menganut kebudayaan Jawa Tengah yang dibawa oleh Pangeran Diponegoro. Filosofi ukiran-ukiran pada Rumah Joglo ini yaitu pertanian. Ungkapan rasa syukur kepada Tuhan Yang Maha Esa telah dilimpahkan hasil pertanian yang melimpah dan nikmat kepada kesehatan, keselamatan, dan rezeki yang cukup. Bangunan 
masih asli belum pernah direnovasi dilakukan pengecatan tembok yang terlihat kusam, dan untuk ukiran kayu hanya dibersihkan.

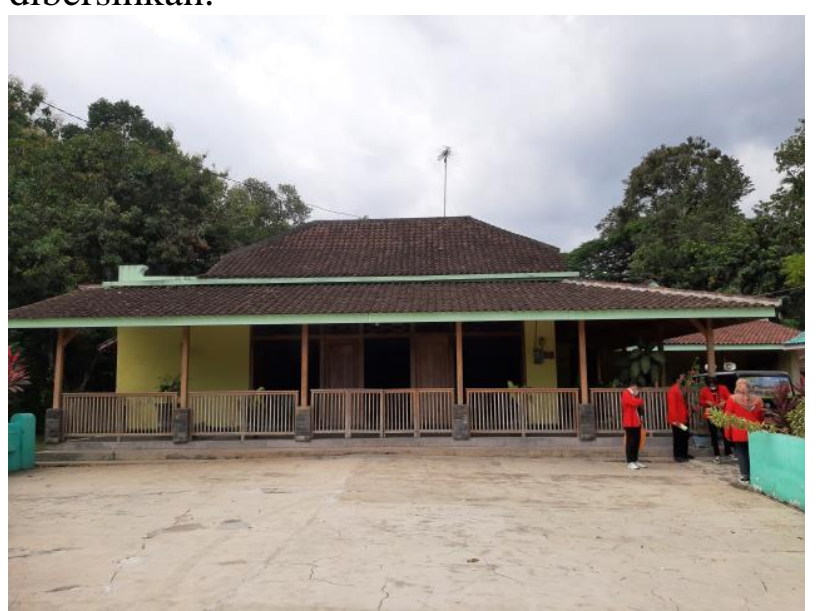

Gambar 1. Rumah Joglo 1

Perencanaan homestay, dilakukan pada Rumah Joglo 1 milik Bapak Sukono, rumah ini masih dengan latar belakang perekonomian agraris dimana terdapat tempat penjemuran padi. Areal ini tidak akan didirikan bangunan melainkan dibiarkan sesuai dengan aslinya. Demikian juga untuk areal parkir telah tersedia sesuai disain yang sudah ada hal ini sangat mendukung adaptasi rumah joglo menjadi tempat penginapan/ homestay. Pada gambar rencana terdapat Pekiwan Ngarep dan Pekiwan Mburi yang terdapat kamar-kamar dengan model dormitory. Tanpa banyak mengubah bentuk asalnya, dalam rumah joglo tersebut masih mempertahankan ruang pusaka, gandok, sentong dan ruang ndalem.

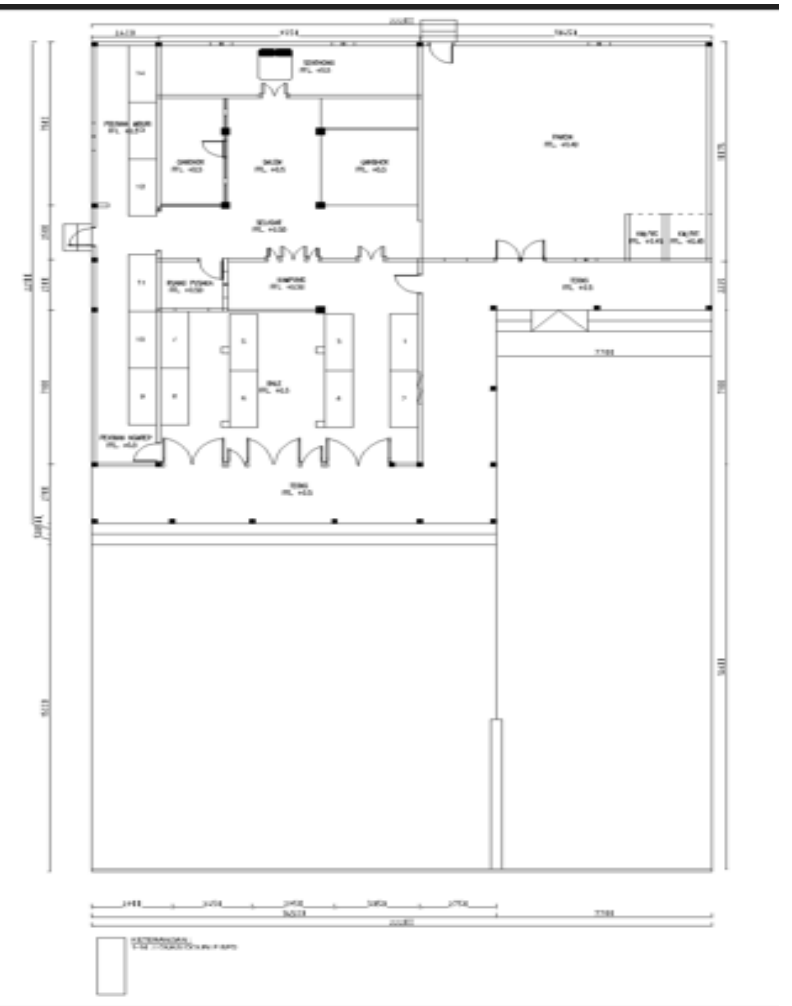

Gambar 2. Denah Rencana Homestay

Rumah Joglo 2: dijadikan sebagai Griya Dedaharan/ Rumah Makan. Dibangun pada tahun 1933 oleh Bapak Suwoto, Desa Minggirsari, Kecamatan Kanigoro, Kabupaten Blitar. Rumah Joglo ini menganut kebudayaan dari timur atau Kemataraman (islam kejawen). Peninggalan seperti karawitan, wewayangan, dan pusaka-pusaka masih terawat dengan baik, sehingga bisa dijadikan sebagi media belajar dan memperkenalkan kepada pengunjung (wisatawan) tentang kebudayaan Jawa, dan yang paling penting yaitu memperkenalkan kepada anak cucu betapa kayanya kebudayaan di Jawa. 


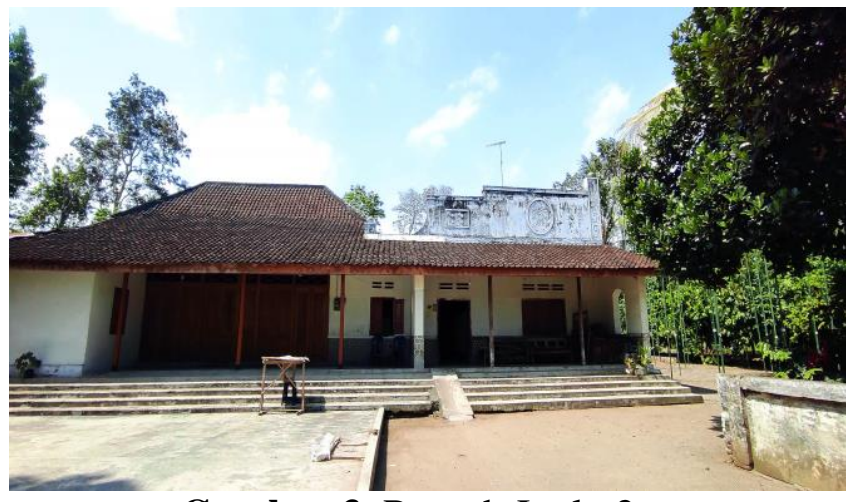

Gambar 3. Rumah Joglo 2

Seperti Rumah Joglo 1, pada Rumah Joglo 2 tidak merubah area tempat jemur padi dan area parkir yang telah ada. Perencanaan Griya Dedaharan ini hanya mengadaptasi penempatan interior tanpa mengubah bagian-bagian dari ruangan aslinya yang terdiri dari teras, bale, gandok, kampung, omah, pawon dan lorong atau koridor yang ada dalam rumah.

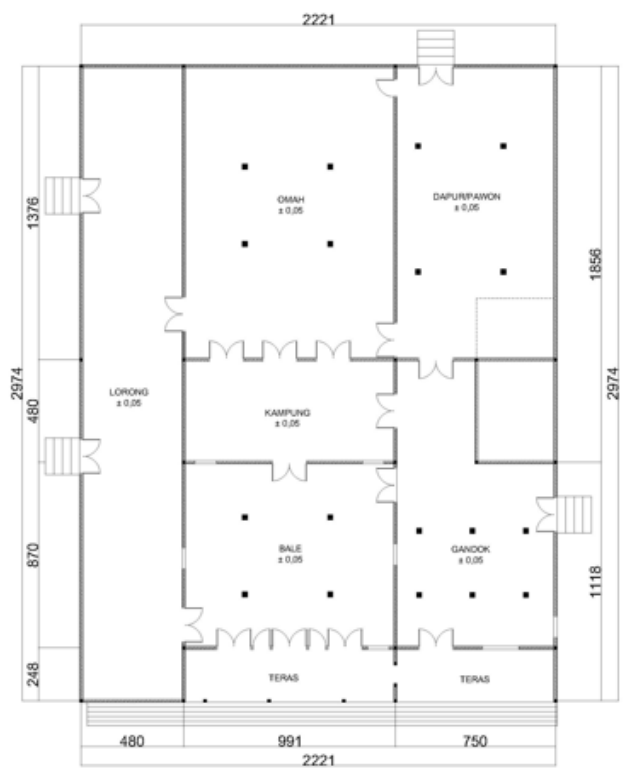

Gambar 4. Denah Rencana Griya Dedaharan

Adaptasi interior dilakukan pada ruang bale yang aka dijadikan sebagai ruang makan dengan dilengkapi furniture serta ornamentornamaen yang sangat kental dengan nuansa Jawa dan tidak meninggalkan budaya Jawa sama sekali, walaupun masih memungkinkan dipadukan dengan hiasan dekorasi dan interior modern.

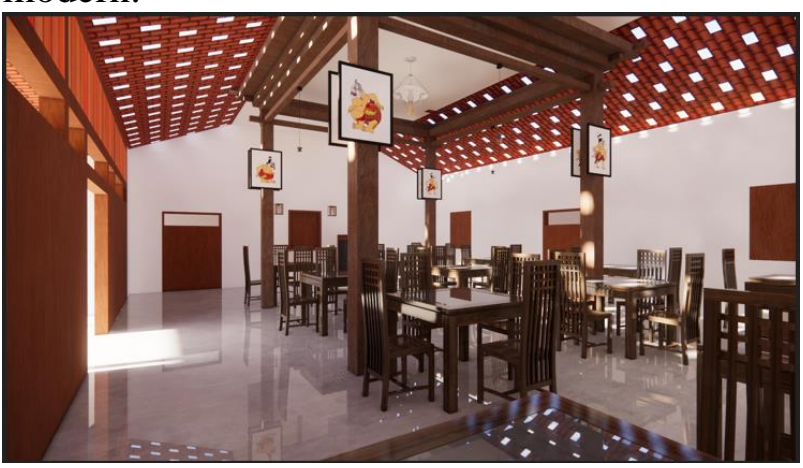

Gambar 5. Interior Griya Dedaharan

Sementara itu ruang cuci piring terletak pada bagian lorong, untuk memudahkan lalulintas dalam rumah agar tindak terjadi kontra dengan petugas yang menghidangkan makanan.

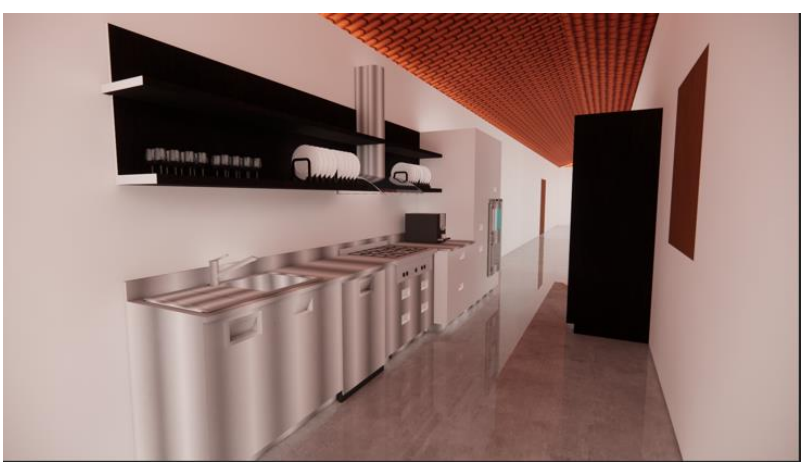

Gambar 6. Ruang Cuci Piring

Rumah Joglo 3, merupakan lokasi yang paling dekat dengan Kantor Kepala Desa Minggirsari yang akan digunakan sebagai ruang pamer produk-produk Desa Minggirsari, ruang belajar, ruang diskusi dan perpustakaan.

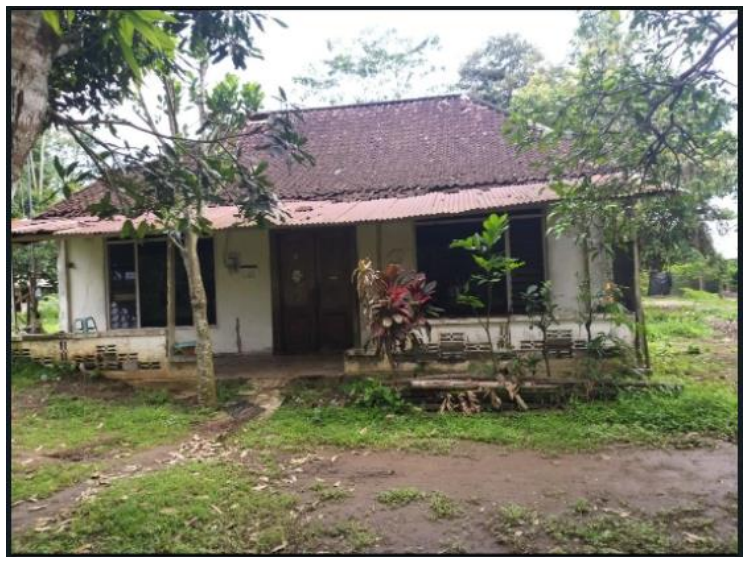

Gambar 7. Rumah Joglo 3 
Kondisi rumah joglo 3 ini sangat memprihatinkan karena para ahli waris berdomisili di luar desa. Rumah joglo 3 ini berdiri di area yang sangat luas dimana bersebelahan dengan masjid milik desa yang sedang di bangun.

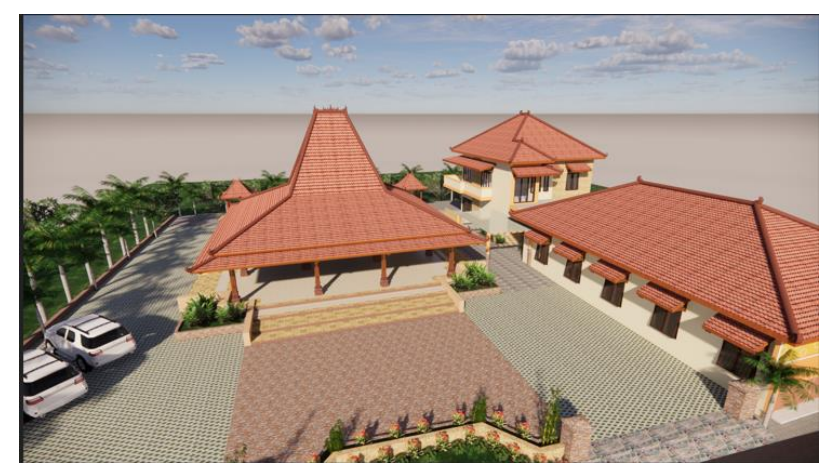

Gambar 8. Rencana Ruang Pamer, Ruang Belajar dan Diskusi

\section{Kesimpulan}

Dari kegiatan Matching-Fund yang dilaksanakan di Desa minggrisari Kecamatan Kanigoro, Kabupaten Blitar hasil yang didapatkan sebagi berikut :

1. Dengan pengoptimalan fungsi dari Rumah Joglo sebagai pendukung Desa Wisata, sehingga mampu beradaptasi dengan lingkungan dan masyarakat untuk mewujudkan tercipatanya Desa Wisata, Desa Minggirsari, Kecamatan Kanigoro, Kabupaten Blitar.

2. Sebagai ciri khas dan daya tarik pengunjung dengan kebudayaan dan kearifan lokal tentang asalusul Rumah Joglo dan kebudayaan yang melatarbelakangi Rumah Joglo tersebut yang berada di Desa Minggirsari, Kecamatan Kanigoro, Kabupaten Blitar.

\section{Saran}

Pada perencanaan alih fungsi 3 rumah joglo di Desa Kanigoro ini belum sepenuhnya menerapkan pakem atau aturan penempatan ruang-ruang sesuai dengan filosofi rumah tradisional joglo secara penuh. Untuk kegiatan pengabdian masyarakat selanjutnya dapat dilakukan perencanaan rumah joglo sesuai aturan yang benar walaupun terdapat adaptasi fungsi menjadi bangunan komersil namun harus tetap mempertahankan budaya bangsa yang adi luhung dan karena memiliki makna serta maksud untuk keseimbangan dalam kehidupan.

\section{Ucapan Terima Kasih}

Ucapan terima kasih kepada Tuhan Yang Maha Esa atas segala kelancaran pelaksanaan kegiatan Matching-Fund tahun 2021 di Desa Minggirsari Kecamatan Kanigoro, Kabupaten Blitar, Jawa Timur dapat berjalan dengan lancar. Terima kasih kami ucapkan kepada Perangkat Desa Desa Minggirsari, Kecamatan Kanigoro, Kabupaten Blitar, Jawa Timur, atas kesediaan bekerjasama dan perizinan kegiatan Matching-Fund Tahun 2021. Serta ucapan terima kasih kepada pihak LPPM Universitas 17 Agustus 1945 Surabaya atas semua bantuan pendanaan administratif sehingga kegiatan Matching-Fund Tahun 2021 sebagai bentuk pengabdian kepada masyarakat dapat dilaksanakan dengan baik dan lancar. Serta ucapan terima kasih yang sebesarbesarnya kepada Kementerian Pendidikan Kebudayaan Riset dan Teknologi Republik Indonesia yang telah memberikan Dana Hibah Matching Fund Tahun Anggaran 2021 untuk Universitas 17 Agustus 1945 Surabaya.

\section{Daftar Pustaka}

Brambel. (2020). Joglo: Rumah Adat Jawa Timur yang Kaya Budaya dan Filosofi. Brambel Journal. https://www.bramblefurniture.com/journal/ru mah-adat-jawa-timur-joglo/

Ernawan, M., TRIJANA, E., \& Ghozali, R. (2016). Analisis Pendapatan Usaha Peternakan Sapi Perah Laktasi. 10(2), 25-40.

Gautama, B. P., Yuliawati, A. K., Nurhayati, N. S., Fitriyani, E., Pratiwi, I. I., \& Indonesia, U. P. (2020). PENGEMBANGAN DESA WISATA 


\begin{tabular}{lrr} 
MELALUI & \multicolumn{2}{r}{ PENDEKATAN } \\
PEMBERDAYAAN & \multicolumn{2}{r}{ MASYARAKAT. } \\
BERNAS: Jurnal & Pengabdian & Kepada \\
Masyarakat, & $1(4)$, & $355-369$. \\
https://doi.org/https://doi.org/10.31949/jb.v1i4 \\
.414
\end{tabular}

Maria Damiana Nestri Kiswari. (2019). Identifikasi Perubahan Fungsi Ruang pada Rumah Tinggal Joglo. PRAXIS, 2(1), 49-65.

Sumardiyanto, S., Antariksa, A., \& Salura, P. (2016). MAKNA RUANG PUBLIK PADA RUMAH TRADISIONAL MASYARAKAT JAWA KASUS STUDI: DESA JAGALAN KOTAGEDE YOGYAKARTA. NALARs, 15(1). https://doi.org/10.24853/nalars.15.1.112

WIBAWA, B. A., WIDIASTUTUI, K., \& NINDITA, V. (2019). EKSISTENSI DAN KEBERLANJUTAN KAMPUNG JOGLO DALAM MASYARAKAT, BUDAYA DAN LINGKUNGAN ASLINYA. Jurnal Teknik Sipil Dan Arsitektur, 24(1). https://doi.org/10.36728/jtsa.v24i1.819 